Contract No. and Disclaimer:

This manuscript has been authored by Savannah River Nuclear Solutions, LLC under Contract No. DE-AC09-08SR22470 with the U.S. Department of Energy. The United States Government retains and the publisher, by accepting this article for publication, acknowledges that the United States Government retains a non-exclusive, paid-up, irrevocable, worldwide license to publish or reproduce the published form of this work, or allow others to do so, for United States Government purposes. 


\title{
Effects of Extreme and Unusual Conditions on LANA Alloys: Interim Report, FY14
}

\author{
Kirk L. Shanahan \\ Savannah River National Laboratory \\ Bldg. 999-2W \\ Aiken, SC, USA 29808
}

April 25, 2014

Savannah River National Laboratory

Savannah River Nuclear Solutions, LLC

Aiken, SC 29808

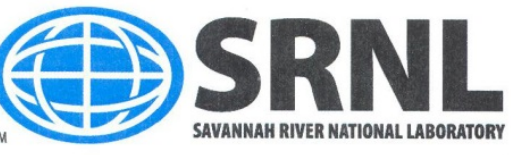

Prepared for the U.S. Department of Energy under contract number DE-AC09-08SR22470. 


\title{
Effects of Extreme and Unusual Conditions on LANA Alloys: Interim Report, FY14
}

\author{
Kirk L. Shanahan
}

April 25, 2014

\subsection{Introduction}

In early FY14, funding was offered to allow pursuit of the objectives outlined in "Effects of Extreme and Unusual Conditions on LANA Alloys: Task Technical and Quality Plan (U)", SRNL-RP-2013-00778 (herein called the "TTP"1 $)$. This report addresses the milestone "Write Interim Report". Herein, a summary of the research results obtained through March 31, 2014 will be presented. Additionally, activities and obstacles to be expected for meeting the TTP milestones will be reported.

\subsection{Background}

As noted in the TTP, previous scouting work on samples of a LANA85 material procured by SRNL for the prototype FISH ("Four-Inch Short Hydride bed") bed has suggested that there is a change in material performance when it is heated at slightly higher than normal temperatures at high hydrogen loadings. (Note that LANA = Lanthanum-nickel-aluminum, trailing digits are taken from the ' $x$ ' value in the generic formula, $\operatorname{LaNi}_{(5-x)} \mathrm{Al}_{x} ;$ LANA85 can also be written as LANA0.85, its specific chemical formula is $\operatorname{LaNi}_{4.15} \mathrm{Al}_{0.85}$.)

Previously, 4 samples were loaded to 4 different loading levels and heated for $\sim 1$ year at $240^{\circ} \mathrm{C}$. The isotherms of the material after the treatment showed slight losses in working capacity in proportion to the loading level, and the most highly loaded sample showed massive changes in the isotherm to the point that a dual plateau isotherm was observed. These isotherms are shown in Figure 1. Subsequently, a single sample of the same material was prepared and heated at $240^{\circ} \mathrm{C}$ with high $\mathrm{H}$ loading for short periods of time, whereupon the isotherms were determined on the treated material. These studies showed a continuous plateau pressure depression, which was reasonably rapid during the first month of treatment, but slowed down considerably in subsequent months of treatment up to a total treatment time approaching 6 months. A plot of the $240^{\circ} \mathrm{C}$ desorption isotherm plateau pressure vs. the treatment time is given in Figure 2 (both aging and isotherm determination was at $240^{\circ} \mathrm{C}$ on this sample).

Generally, this effect has previously been observed in Pd alloys ${ }^{2}$, and the process of heating a fully loaded hydride material under 'high' pressure is called Hydrogen Heat Treatment and abbreviated as HHT. 'High' is not explicitly defined but typically is significantly over the plateau pressure. One of the objectives of this study is to determine the effects of varying the treatment temperature and overpressure conditions.

The TTP proposed research aimed at determining:

a) the rate at which these changes occurred and the effect of initial conditions, especially in the early phases of HHT, 
b) whether or not different LANA alloys would show similar effects, and

c) whether common contaminants/poisons impacted LANA alloy hydride chemistry similarly to what had been found for Pd and Pd-alloy hydride chemistry.

In prior SRNL work, it has been noted that pre- or co-adsorption of CO on Pd alloys can almost completely block $\mathrm{H}$ absorption ${ }^{3,4}$. Similarly, from the open literature, $\mathrm{S}$ pre-adsorption can completely block $\mathrm{H}$ absorption in many metals and alloys. $\mathrm{CO}$ has also been noted to block hydrogen absorption in LANA alloys ${ }^{5,6,7}$. Additionally it would be useful to determine a method to remove the contaminants from the LANA material in a manner that might be implemented in the Tritium Facility (TF).

\subsection{Objectives A and B - Characterizing Rates and Conditions Causing HHT Effects}

\subsection{Experimental Approach}

The previous scoping studies used a LANA85 material procured for the prototype FISH bed development program. Raw alloy was obtained in ingot form from GfE (Gesellschaft für Elektrometallurgie), crushed for SRNL by Ergenics, and subsequently solution alloyed for SRNL by Hydrogen Components, Inc. Substantial prior work on the virgin material had established its isotherm properties. Herein, this material will simply be referred to as the GfE material.

Initially, to address objective B, 5 new samples of LANA materials were prepared and studied. One of the samples was a second type of LANA85 procured in the 1980's, which has since been stored under ambient inside conditions (Ergenics lot number 1138-V-2, sample designation LANA85_EXOP1). Two samples were different lots of LANA75 material: one was material that had also been procured in the 1980's and stored (Ergenics lot 1316-V-2, sample designation LANA75_EXOP2), and the second was taken from archival material of LANA75 that had been procured for the TCON project of the mid-2000's. This lot of material was manufactured by Ergenics and was comprised of a blend of 3 heats, designated as V-200767, V-200797, and V-200322 (sample designation LANA75_EXOP3). This material was used in the replacement LANA75 beds installed in the TF in 2004 and will be referred to herein as the 'TCON blend' material.

The first 3 samples (LANA85_EXOP1, LANA75_EXOP2, and LANA75_EXOP3) were loaded and heated at $240^{\circ} \mathrm{C}$ for $\sim 1$ month to compare to the second scoping sample study results mentioned above. One additional sample of each of the LANA75 materials was also prepared (sample designation LANA75_EXOP4, lot 1316-V-2; sample designation LANA75_EXOP5, TCON blend) and hydrogen heat treated for $\sim 1$ week. Diagnostic isotherms were then recorded on these 5 samples. After completing these isotherms, the 1-month aged samples were returned for an additional month of HHT. At the end of this reporting period, the 1 week samples were nearing completion of isotherm acquisition and the 1 month samples had just begun their $2^{\text {nd }}$ month of HHT. However, a Safety Stand-down has interrupted this work and all HHT is currently on hold but will hopefully resume shortly.

The original scoping study (see Fig. 1) samples were initially loaded on the PCTPro with $\mathrm{H}_{2}$ to 195,241 , and 374 psia (13.1, 16.2, 25.1 bar, respectively) for the LOW, MID, and HIGH loading levels, respectively. 
Subsequent sample loadings were also done on the PCTPro, typically to pressures of $\sim 40$ bar ( $\sim 580$ psia) +/- 1 bar (14.51 psia), with the following exceptions:

1. Sample LANA75_EXOP3 was loaded to 44.3 bar (638 psia) for its first HHT.

2. Sample LANA85_GFE5 was initially loaded to lower pressures, between 25-35 bar (363-508 psia), whereas the last 2 loadings were done at 40-42 bar (580-609 psia).

Only LANA85_GFE5 has been loaded with $\mathrm{D}_{2}$. Out of 8 charges, the first 4 and the last one were done with $\mathrm{H}_{2}$, and the remaining 3 with $\mathrm{D}_{2}$. All other samples and most loadings on GFE5 were done using $\mathrm{H}_{2}$. The samples typically showed a slight drop in pressure over the HHT; however, it is not clear if this is a result of leaks or some other factor(s). Data analysis comparing the $\mathrm{H}_{2}$ to $\mathrm{D}_{2}$ results has not yet been completed.

\subsection{Results and Discussion}

To aid in recalling sample designations and processing parameter, Table 1 shows the sample designation, material source, and aging conditions relevant to this report. For comparison, the previous results of the 350 day aging of $4 \mathrm{GFE} \mathrm{LANA85}$ samples at $240^{\circ} \mathrm{C}$ are shown in Figure 1, illustrating a small capacity drop proportional to the HHT loading pressure and the severe change in shape of the hydrogen desorption isotherm for the 'fully' loaded sample, i.e. where the loading was high enough for the sample to be fully in the $\beta$-phase. (All 4 of these samples have been retired.) Figure 2 plots the $240^{\circ} \mathrm{C}$ desorption isotherm plateau pressure of a sample of the GfE LANA85 material that has been heated at $240^{\circ} \mathrm{C}$ for $\sim 6$ months under full loading. This sample continues to be used in this study and is designated as LANA85_GFE5. The prior results using this sample are presented in Figure 2 as a plot of plateau pressure vs. the HHT treatment time (days). It can clearly be seen that the depression progresses linearly (at least so far) once an initial large drop is experienced somewhere in the first 20 days. Samples LANA75_EXOP4 and_EXOP5 are being studied at short intervals (typically $\sim 1$ week of aging at a time) to try to more closely determine when this occurs.

It should be noted that experimental work on the second GfE material sample LANA85_GFE5 has shown that the absorption/desorption kinetics of the material slowed down considerably after HHT. The $80^{\circ} \mathrm{C}$ isotherm determination is no longer feasible on this sample. As such, higher temperature isotherms are being examined, which has led to an effort to obtain some high temperature data on the new samples in preparation for being unable to get low temperature isotherms later in the program. Of course higher temperatures means higher pressures and the primary isotherm determination manifold in HTRL Lab 134 is limited to 150 psia feed pressures. Strategies have been implemented to load at low temperature and then study the sample at high temperature; however, this essentially limits the ability to obtain high temperature absorption data. Later, the samples may be transferred to our high pressure manifold, a commercial instrument called the PCTPro, to obtain the absorption isotherms.

It should also be noted that the isotherms obtained to date on the second GfE material sample do not show the dual plateau structure. In Figure 3, the linear fit to the data of Figure 2 is extended out to 1 year, which is past the actual HHT time on the samples used in Figure 1. Since the line intercepts the 0 pressure line at $<350$ days, and since a zero pressure is unlikely, this would suggest that there might be a 
mechanism change for HHT response as the sample undergoes HHT. Presumably, when the plateau pressure decreases enough, a second phase may begin to develop instead of experiencing continued plateau pressure depression. We continue to treat LANA85_GFE5 to examine this possibility, and the LANA85_EXOP1 sample will also be used to determine whether or not a different LANA85 material behaves the same.

The results from the other 5 samples obtained at $80^{\circ} \mathrm{C}$ using both protium $\left(H_{2}\right)$ and deuterium $\left(D_{2}\right)$ are presented in Figures 4 through 14. Figures 4 through 9 present the results for the first 3 new samples, which have experienced 1 month of $\mathrm{HHT}$, in the form of protium followed by deuterium isotherms. Figures 9 through 14 present only the deuterium results for the $4^{\text {th }}$ and $5^{\text {th }}$ samples (LANA75_EXOP4 \& _EXOP5) obtained after $\sim 1$ week of HHT. Figure 15 presents some of the partial results obtained at $150^{\circ} \mathrm{C}$ using $\mathrm{D}_{2}$ on LANA75_EXOP5. In summary, all of the results so far show plateau pressure depression, including the partial isotherm shown in Figure 15. What is intriguing is when the dual plateau structures are observed. Samples 1, 2, and 3 (LANA85_EXOP1, LANA75_EXOP2, LANA75_EXOP3) have differing behaviors. In agreement with the prior studies using the GfE material (LANA85_GFE5), no dual plateau structure was evident after 1 month of HHT in LANA85_EXOP1.

In contrast, the LANA75 samples (EXOP2 and EXOP3) both show a dual plateau isotherm with a transition to the higher pressure plateau beginning at a nominal $\mathrm{Q} / \mathrm{M}$ value of $\sim 0.5(\mathrm{Q}=\mathrm{H}+\mathrm{D}(+\mathrm{T}))$. For example, Figure 6 a shows $80^{\circ} \mathrm{CH}_{2}$ isotherms from a lot of Ergenics LANA75 (lot 1316-V-2) (EXOP2) aged for $\sim 1$ month at $240^{\circ} \mathrm{C}$ under high hydrogen pressure. A transition point is noted at $\mathrm{H} / \mathrm{M} \sim 0.5$, where the plateau undergoes a downward shift (as observed while going from high to low loading). Figure 6b shows just the desorption curve of the aged material to remove any visual interference from the virgin data. This curve should be compared to the "HIGH" isotherm of Figure 1. Both clearly show the dual plateau structure. Likewise, the deuterium isotherms from this sample (Figure 7) also show the dual plateau, and both the $\mathrm{H}_{2}$ and $\mathrm{D}_{2}$ isotherms from LANA75_EXOP3 (Figures 8 and 9) do as well.

When the less extensively treated LANA75 sample results are examined, the picture is less clear, primarily because the effect is smaller, as would be expected with the lesser aging times. The desorption curves do not seem to show much of a transition at all, instead perhaps illustrating a commonly observed feature in tritium aging studies, where the lower $\mathrm{O} / \mathrm{M}$ portion of the plateau is no longer flat and shows irregular decreases as $\mathrm{Q} / \mathrm{M}$ decreases, i.e. a 'rounded' appearance. The plateaus in the absorption isotherms however can be seen to be approximately flat while also being positively sloped. More aging will hopefully resolve these into clearer versions of plateaus.

LANA75_EXOP4 appears to show the smallest trace of the beginning of a dual plateau transition at D/M of 0.25 only in the absorption isotherm of Figure 10 . Figure 11 is a replot of the data in Figure 10 with the virgin data excluded to more clearly see this slight shift in plateau level without the interfering virgin material points. A similar slight shift in level is seen in the absorption isotherm of LANA75_EXOP5, but in this case at the approximate $\mathrm{D} / \mathrm{M}$ of $\sim 0.38$ in Figure 12 . The data is again replotted in Figure 13 without virgin material data to allow the transition to be seen more clearly. There are actually two sequential absorption/desorption isotherm cycles shown in Figure 12 (and 13) to test the isotherm's stability to cycling (no change noted). To further aid in clarification, Figure 14 was constructed by merging the two 
absorption isotherms into one, likewise with the desorption isotherms. The merging was accomplished by simple combination of isotherm data sets into one, followed by sorting based on increasing pressure. This eliminates excess tie-lines between points and more clearly shows the transition point at $\mathrm{D} / \mathrm{M} \sim 0.38$. Upon careful inspection, one might be able to see a similar appearance of a level shift in the desorption curve; however, that transition is very close in size to the error level of the method, and thus may not be real. (The scatter of the data points in the $\mathrm{D} / \mathrm{M}$ region of $<0.05$ indicates a reproducibility level of $\sim 0.02$ $0.03 \mathrm{D} / \mathrm{M}$ units, which is typical for this kind of data.) This may be clarified in the next set of data to be obtained after 2 weeks of HHT, where presumably the transitions will have strengthened.

The explicit origin of the dual plateau structure is not known. Clearly, the dual plateau indicates two different chemical phases are now present in the material, brought on by HHT. This might imply different chemical composition in different parts of the material. In the untreated material with a single plateau, the isotherms are interpreted with a picture that has the $\beta$-phase forming precipitates in the majority $\alpha$-phase until the $\alpha$-phase has been fully consumed, which presumes the formation of the hexahydride, $\mathrm{LaNi}_{5-x} \mathrm{Al}_{x} \mathrm{H}_{6}$. However, literature data also indicate that some researchers ${ }^{8}$ have observed the formation of the intermediate trihydride, $\mathrm{LaNi}_{5-\mathrm{x}} \mathrm{Al}_{\mathrm{x}} \mathrm{H}_{3}$, which produces a dual plateau isotherm with a transition point at $\sim 50 \%$ of full loading, i.e. $\mathrm{Q} / \mathrm{M} \sim 0.3-0.4$, depending on the full capacity of the material. Figure 16 shows data obtained here at SRNL on a LANA30 material ${ }^{9}$ showing a dual plateau structure occurring in virgin material. This structure likely reflects the trihydride formation prior to full hexahydride formation.

The observation made on LANA75_EXOP5, where the putative transition occurs at $\mathrm{Q} / \mathrm{M} \sim 0.38$, suggests the trihydride explanation, whereas the LANA75_EXOP4 behavior, where the transition point is at Q/M $\sim 0.25$, does not fit that description. This would potentially suggest the formation of a base alloy compositional change where two average compositions are now mixed in the metal as a more likely explanation for EXOP4. Of course, a compositional change might foster trihydride formation as well, effectively combining both potentially separate causes into one observable effect. Hopefully, the additional data to be obtained as this program progresses will help clarify this issue.

Even more important to the TF is the knowledge of how fast this all might occur in the Plant under normal operating conditions (which could include infrequent operations as well as the normal ones). The data to be gathered from the existing samples and additional new samples studied with different HHT conditions will presumably shed insight on this question.

\section{$\underline{3.3 \text { Interim Conclusions }}$}

Even though limited data (in the whole scope of the project) have been obtained, some preliminary conclusions can be drawn:

1.) LANA75 materials and other LANA85 material also show HHT effects

2.) HHT effects occur differently in LANA75 than in LANA85, but the second lot of LANA85 mimicked the first in that only plateau pressure depression is noted to occur early on (possibly up to 6 months of $\mathrm{HHT}$ ). Therefore, dual plateau isotherms must develop later. 
3.) The differences in HHT response suggest sensitivity to composition, which includes changes found from lot-to-lot in the same nominal material

The project as a whole is progressing, but perhaps somewhat more slowly than originally envisioned. Part of that has been caused by unexpected down time from events such as water outages, ice storms, and safety stand-downs. However, a large quantity of new information has been obtained and new conclusions are being drawn, possibly important to the TF in terms of operating conditions and procurement specifications for replacement LANA materials, which meets the intent of the effort.

\subsection{Equipment Considerations}

This project has required the simultaneous running of multiple samples. The HTRL Lab 134 Manual Manifold 1 (MM1) had 6 test ports split evenly between two sides, but only 1 pressure transducer per side, limiting simultaneous operations to two samples. During this project, additional in-hand pressure transducers have been installed on sub-manifolds that have allowed the simultaneous examination of 4 samples on the MM1. In addition, the gas-inlet manifold connected to the Pfeiffer-Balzers High resolution GAM400 Mass Spectrometer System (which uses air-actuated valves) has been reconfigured to form 2 new submanifolds (Air-Actuated Manifold 1 \&2, AAM1 \& AAM2), adding the potential to run 2 more simultaneous samples. We are modifying the laboratory eHAP to allow operation of these new manifolds and to modify operational restraints to conform to current policies. These operational restraints have required us to order 12-15 new overtemperature protection devices, only 3 of which have been received at this point.

The high pressure capability of HTRL Lab 134 is limited to the commercial instrument known as the PCTPro. While the other manifolds are limited to 150 psia feed pressures, which limits obtaining higher $\mathrm{P}$ and T absorption data, the PCTPro is capable of handling up to 3000 psi. Unfortunately, this instrument is becoming aged, and has recently suffered some equipment issues (resolved prior to this fiscal year). One item of particular potential significance is the fact that the PCTPro control software is a commercial product that runs on Windows XP, which has just stopped being supported by this Site and the manufacturer. In addition, part of the issues noted above was a computer crash because of a failed motherboard. We are currently operating using an old laptop running XP, but we have no backup identified (we were unsuccessful in getting the software to run on Windows 7 ). If this computer fails, we will be unable to continue this project until an alternate solution is found and implemented, as the PCTPro is used to charge the samples to 30-40 bar (430-580 psia) in the HHT treatments.

\subsection{Contaminant Effects: Objective C - Impact of Common Contaminants/Poisons}

\section{$\underline{4.1 \text { Background }}$}

Contaminants such as $\mathrm{CO}$ (carbon monoxide) and S (sulfur) are known to cause hydrogen absorption/desorption issues in Pd-based materials. Some new materials were developed here at SRNL through joint research with Prof. T. Flanagan from the U. of Vermont to address the CO contamination ${ }^{2}$. The $\mathrm{CO}$ effect could be induced either by adding $\mathrm{CO}$ to the hydrogen or by pre-exposing the Pd-material to $\mathrm{CO}$. The $\mathrm{CO}$ would be retained even after evacuation, as was shown by the continued loss of 
absorption ability. However, heating the material with or without additional oxygen often reverses the problem. Unfortunately, $\mathrm{S}$ is known from the literature to be very difficult to deal with once it has appeared on the Pd material. Also, there has been a study ${ }^{6}$ of the impact of a continuous feed of a COcontaminated hydrogen feed to a LANA material that showed it also hampered hydrogen absorption. The goal of this part of the project is to determine the importance of these factors to TF-type LANA materials. To that end, several experiments were outlined in the TTP to investigate.

\subsection{Progress}

To be able to handle $\mathrm{CO}$ and $\mathrm{S}$ derived from $\mathrm{H}_{2} \mathrm{~S}$, a separate gas handling manifold needed to be built, particularly in light of the $\mathrm{S}$ retention issue in the manifold after exposure to $\mathrm{H}_{2} \mathrm{~S}$, but also because said manifold had to be placed inside a hood for toxicological control in the case of leaks or releases. Parts for this manifold are in hand or on order. A scroll pump has been acquired and air-operated valves were already in hand along with other manifold parts. These parts can now begin to be assembled and tested prior to obtaining permission to proceed (via a signed eHAP). Valve controllers have been ordered that will allow remote valve operation either manually or via computer control. Excess $\mathrm{CO}$ and $\mathrm{H}_{2} \mathrm{~S}$ have been located as well and are in the process of being transferred to the hood in HTRL Lab 134. Nearly all hardware and chemicals have been acquired or ordered at this time, and the immediate future direction will be to assemble and test the manifold, write the eHAP documentation, and get it approved. At that point, the plan is to first work with $\mathrm{CO}$, as it has little memory effect, to determine its effect on LANA characteristics, followed by the use of $\mathrm{H}_{2} \mathrm{~S}$ to deposit $\mathrm{S}$ on the LANA samples.

\subsection{Conclusions and_Path Forward}

Progress to date has been good despite setbacks as a result of unexpected shutdowns and experimental difficulties due to capability expansion. Even with the limited amount of interim data, some conclusions could be drawn: all LANA materials show plateau pressure depression due to HHT effects, different LANA materials show additional effects to differing extents, and these responses indicate minor compositional variation, which can result in noticeably different behavior over time, indicating that lotto-lot variations can be important. One reason to study HHT effects is that the plateau pressure depression mimics depressions occurring due to tritium aging effects. Thus, the implication that lot-tolot variations may be important in HHT can potentially infer that tritium aging effects may show such dependencies as well. Work continues to quantify these behaviors, and to build and implement a manifold for handling and studying the effects of toxic substances known to be poisons for hydrogen absorption in LANA materials.

\subsection{References}

1. "Effects of Extreme and Unusual Conditions on LANA Alloys: Task Technical and Quality Plan(U)", Kirk L. Shanahan, SRNL-RP-2013-00778

2. "A possible role for hydrogen-induced lattice migration in alloy materials processing", T. B. Flanagan and H. Noh, J. Alloys and Compounds 231 (1995) 1

3. "Inhibition by gaseous impurities of hydrogen absorption by Pd and internally-oxidized Pd-Al alloys", T. B. Flanagan, D. Wang, K. L. Shanahan, Phys. Chem. Chem. Phys. 2 (2002) 4976 
4. "Permeation of hydrogen through pre-oxidized Pd membranes in the presence and absence of CO", D. Wang, Ted B. Flanagan, Kirk L. Shanahan, J. Alloys and Compounds 372 (2004) 158

5. "Cyclic Response of Reversible Hydriding Alloys in Hydrogen Containing Carbon Monoxide", P. G. Eisenberg, P. D. Goodell, J. of the Less-Common, 89 (1983) 55

6. "Effects of carbon monoxide on the hydriding reactions of the untreated and fluorinated LaNi4.7Al0.3 alloys", X.-L. Wang, K. Iwata, S. Suda, J. of Alloys and Compounds 231 (1995) 829

7. "Hydrogen purification using fluorinated LaNi4.7Al.3 alloy", X.-L. Wang, K. Iwata, S. Suda, J. of Alloys and Compounds 231 (1995) 860

8. "Stability of the hydrogen absorption and desorption plateaux in LaNi5-H. Part 4: thermal history effects", C. E. Buckley, E. MacA. Gray, E. H. Kishi, J. of Alloys and Compounds 231 (1995) 460

9. "Materials Characterization for the Unloading Line B Project (U)", Kirk L. Shanahan, SRNL-STI2011-00750 
Table 1. Summary of Sample Identification Information and Processing Conditions

Sample ID

"Prior Study" (Fig. 1)

LANA85_GFE5

( $2^{\text {nd }}$ scoping study)

LANA85_EXOP1

LANA75_EXOP2

LANA75_EXOP3

LANA75_EXOP4

LANA75_EXOP5
Manufacturer ID

GfE Material

GfE Material

Ergenics lot 1138-V-2

Ergenics lot 1316-V-2

TCON blend

Ergenics lot 1316-V-2

TCON blend $\underline{\text { HHT Processing Conditions }}$

Samples were heated at $240{ }^{\circ} \mathrm{C}$ for $\sim 1 \mathrm{yr}$ at

listed pressures

Sample aged in several $\sim 1$ month periods

Sample aged for $\sim 1$ month

Sample aged for 1 month

Sample aged for $\sim 1$ week

Sample aged for $~ 1$ week 
Figure 1. $80^{\circ} \mathrm{C}_{2}$ absorption/desorption isotherms obtained from 4 GfE LANA85 samples thermally aged for $\sim 1$ year at $240^{\circ} \mathrm{C}$. Protium loadings were: NONE (control sample), LOW (just into the alpha phase), MID (on the plateau), and HIGH (into the beta phase region). Minor capacity losses were noted for all protium-loaded samples, but the HIGH loading produced a dual plateau desorption isotherm.

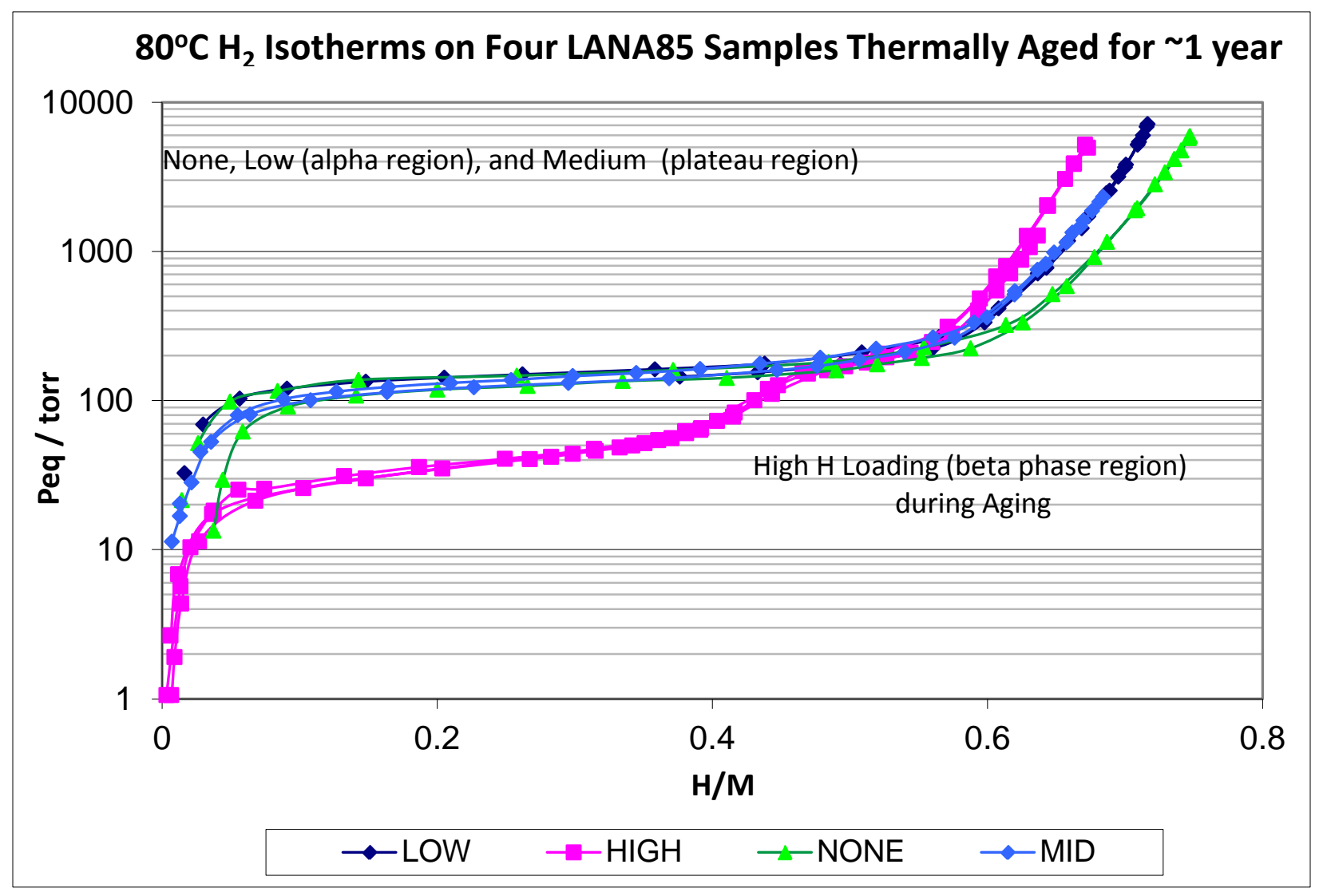


Figure 2. Progressive plateau pressure depression noted for a thermally aged GfE LANA85 sample. Thermal aging occurred at $240^{\circ} \mathrm{C}$, and isotherms were determined the same temperature for this plot. Both absorption and desorption curves were affected, and both showed linear decreases once approximately 20 days of aging had been experienced. Rates were obviously faster in the early days as indicated by the extension to 0 treatment days falling well below the observed virgin material plateau pressures. Least squares lines were fit to the data and the equations and multiple $R^{2}$ values are shown.

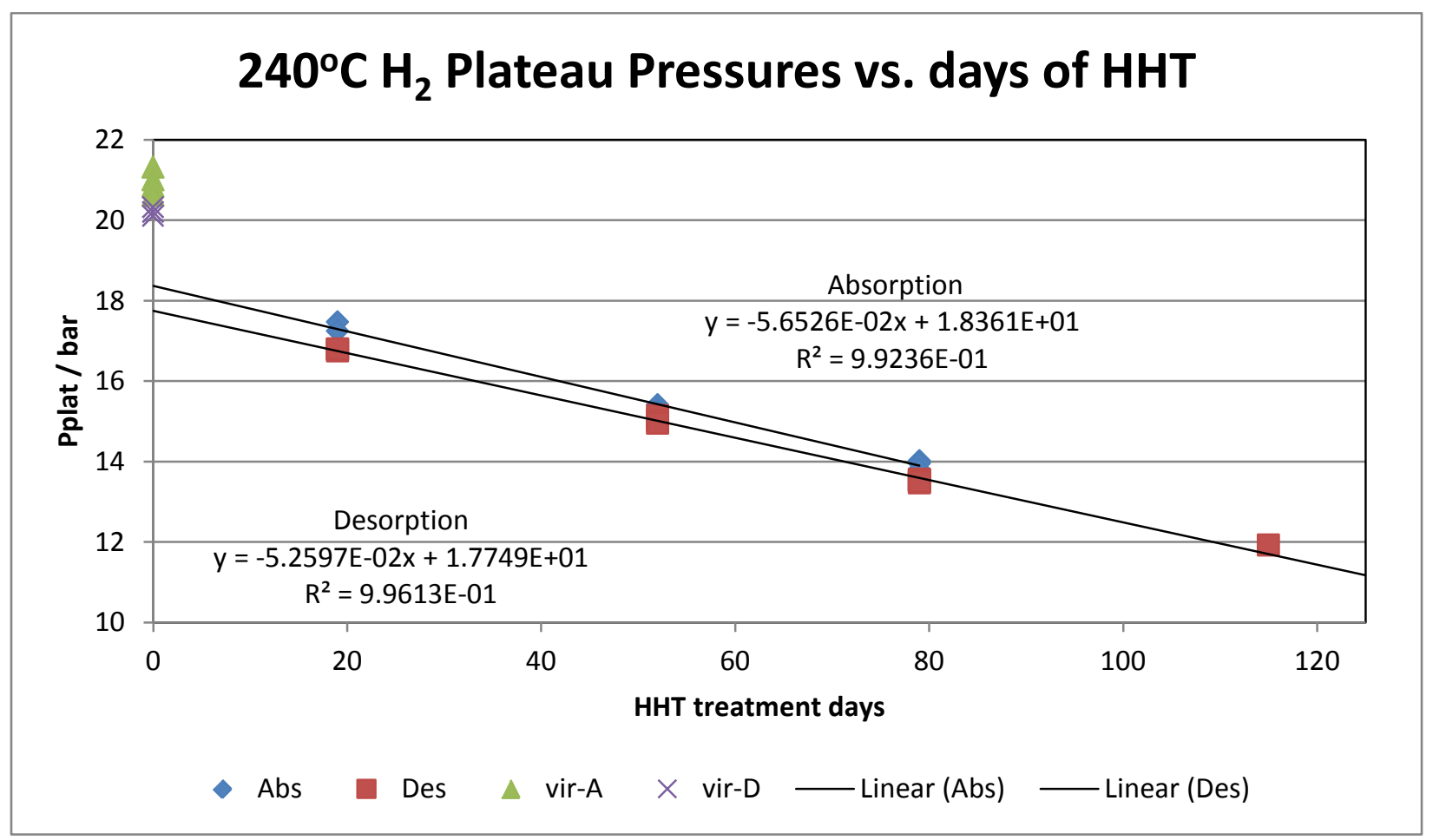


Figure 3. The linear fit of the LANA85_GFE5 sample $240^{\circ} \mathrm{C}$ desorption plateau pressures shown in Figure 2 extended to $\sim 1$ year. The line intersects 0 prior to the age of the initial sample results shown in Figure 1. Since a zero pressure cannot be obtained, it was speculated that the dual plateau might develop after the plateau pressure had dropped sufficiently.

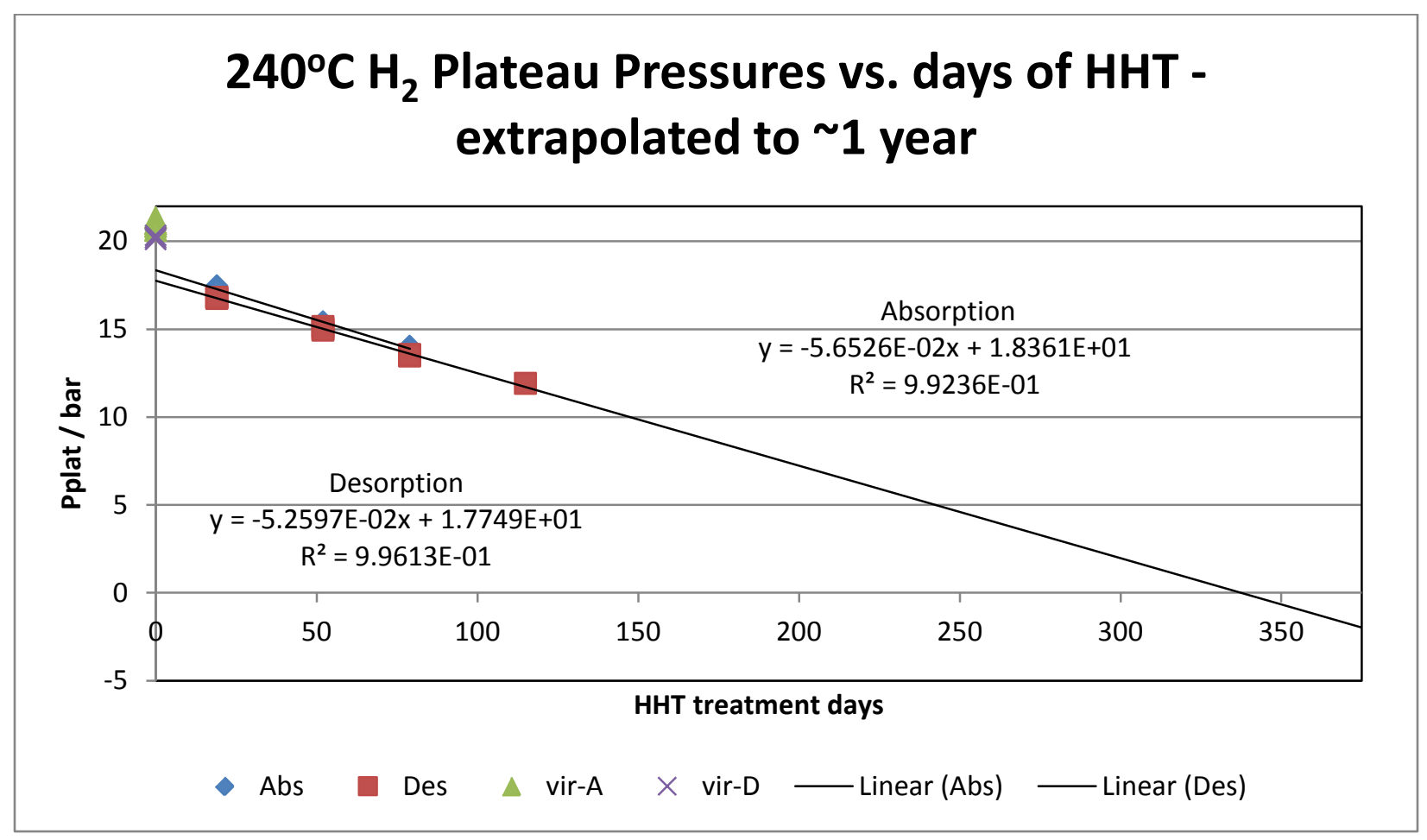


Figure 4. $80^{\circ} \mathrm{C} \mathrm{H}_{2}$ isotherms from a lot of Ergenics LANA85 (lot 1138-V-2). Virgin material results are compared to a desorption isotherm from material aged for $\sim 1$ month at $240^{\circ} \mathrm{C}$ under high hydrogen pressure. A clear plateau pressure depression is observed, with no indication of a dual plateau.

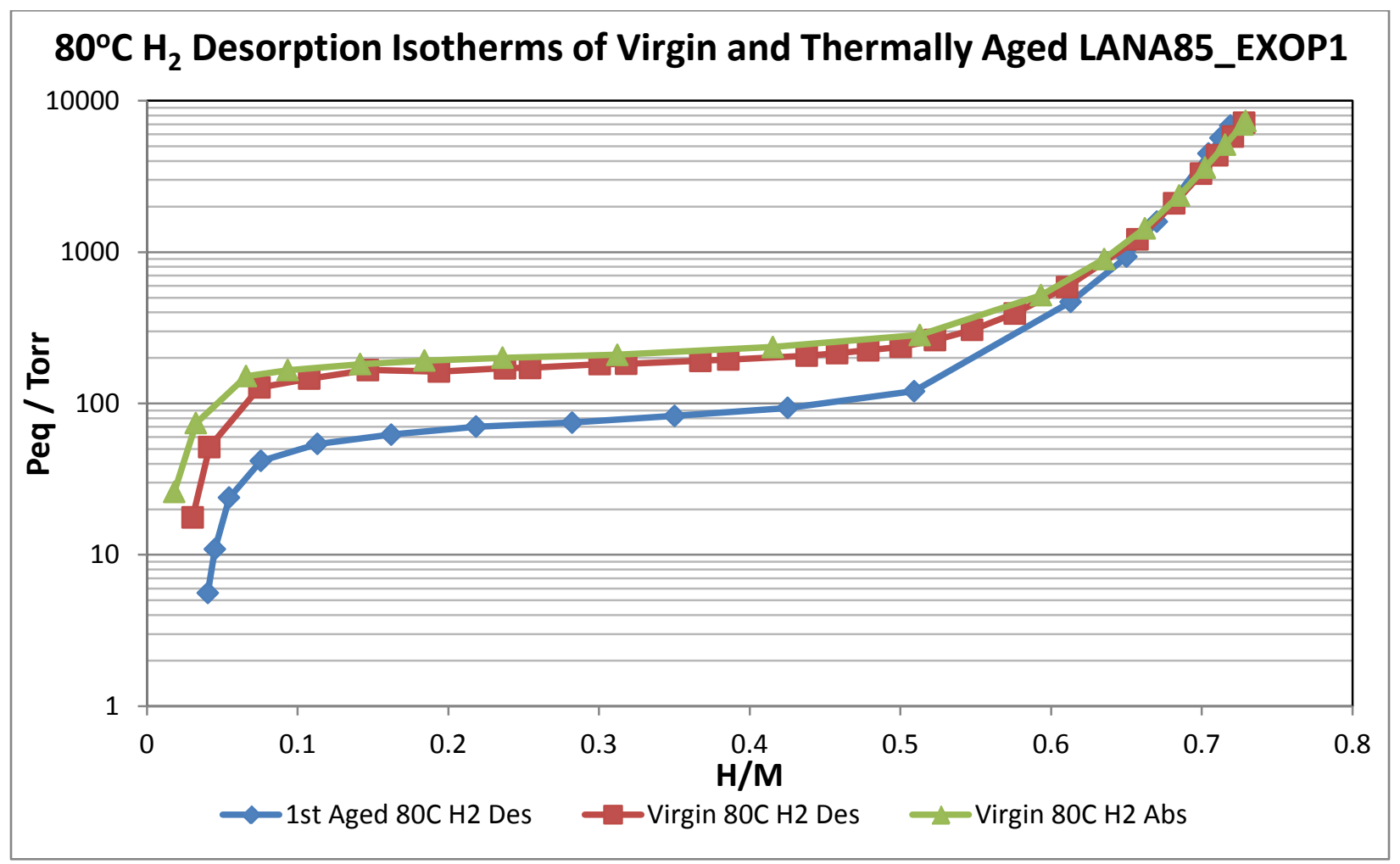


Figure 5. $80^{\circ} \mathrm{C} \mathrm{D}_{2}$ isotherms from a lot of Ergenics LANA85 (lot 1138-V-2). Virgin material results are compared to a desorption isotherm from material aged for $\sim 1$ month at $240^{\circ} \mathrm{C}$ under high hydrogen pressure. A clear plateau pressure depression is observed, with no indication of a dual plateau.

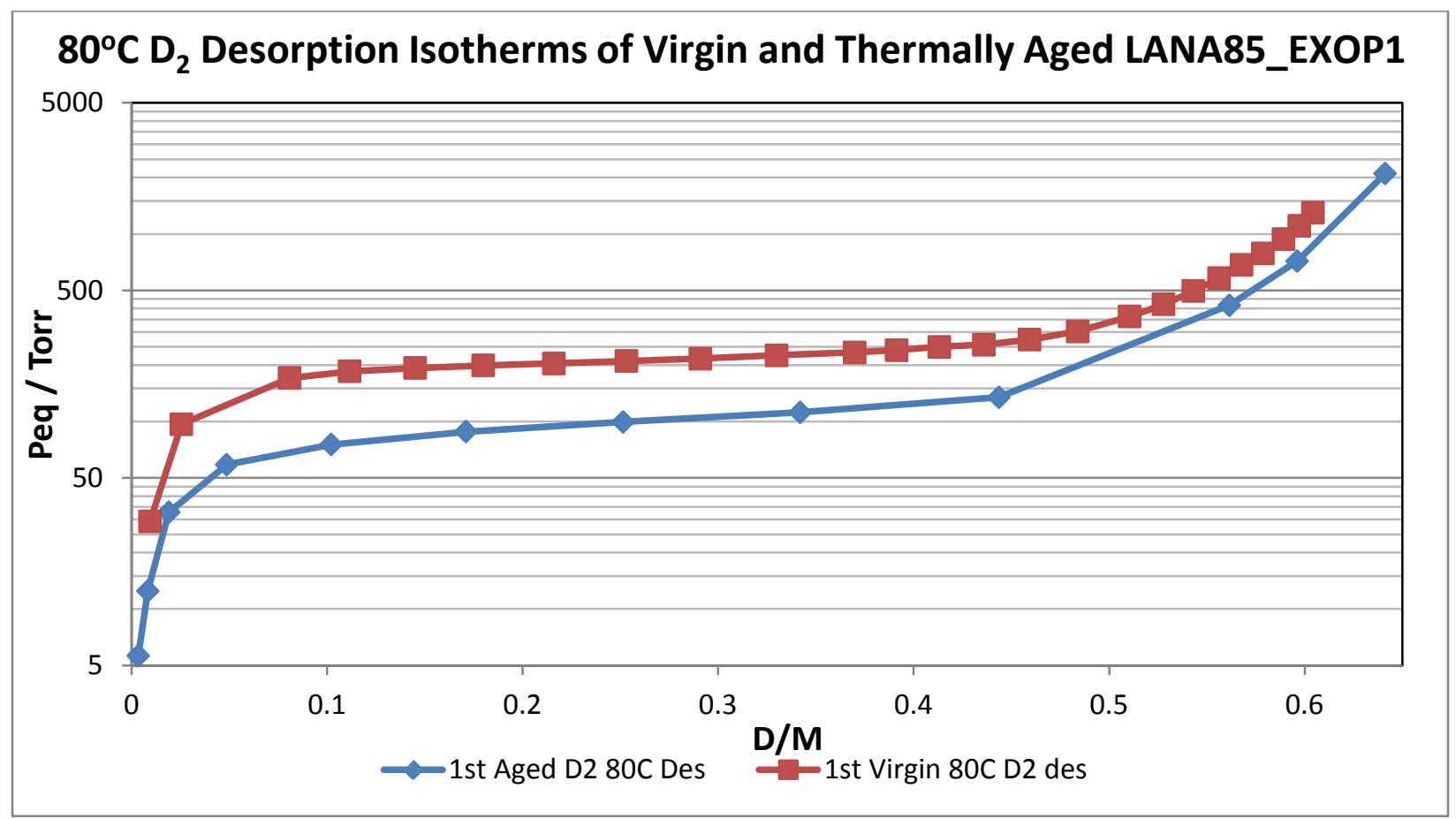


Figure 6a. $80^{\circ} \mathrm{C} \mathrm{H}_{2}$ isotherms from a lot of Ergenics LANA75 (lot 1316-V-2). Virgin material results are compared to a desorption isotherm from material aged for $\sim 1$ month at $240^{\circ} \mathrm{C}$ under high hydrogen pressure. A clear plateau pressure depression is observed and a small dual plateau is observed, beginning at $\mathrm{H} / \mathrm{M} \sim 0.5$.

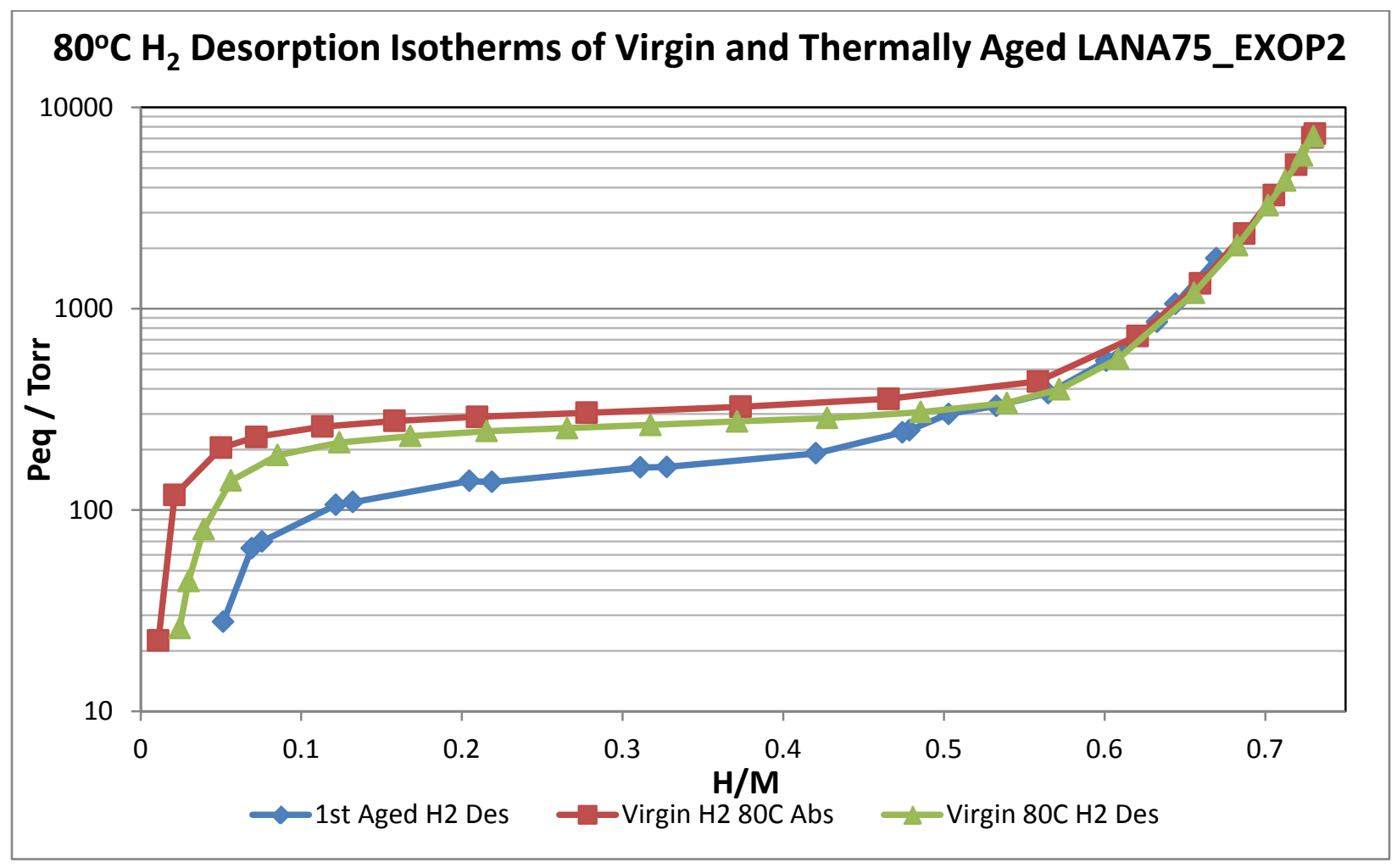


Figure 6 b. The $80^{\circ} \mathrm{C}_{2}$ desorption isotherm from a lot of Ergenics LANA75 (lot 1316-V-2) aged 1 month at $240^{\circ} \mathrm{C}$ under high hydrogen pressure. A clear plateau pressure depression is observed and a small dual plateau is observed, beginning at $\mathrm{H} / \mathrm{M} \sim 0.5$. Virgin material isotherms have been excluded from

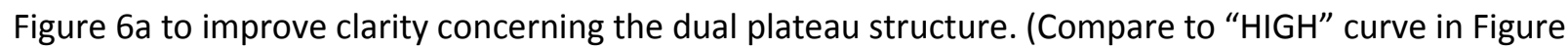
1.)

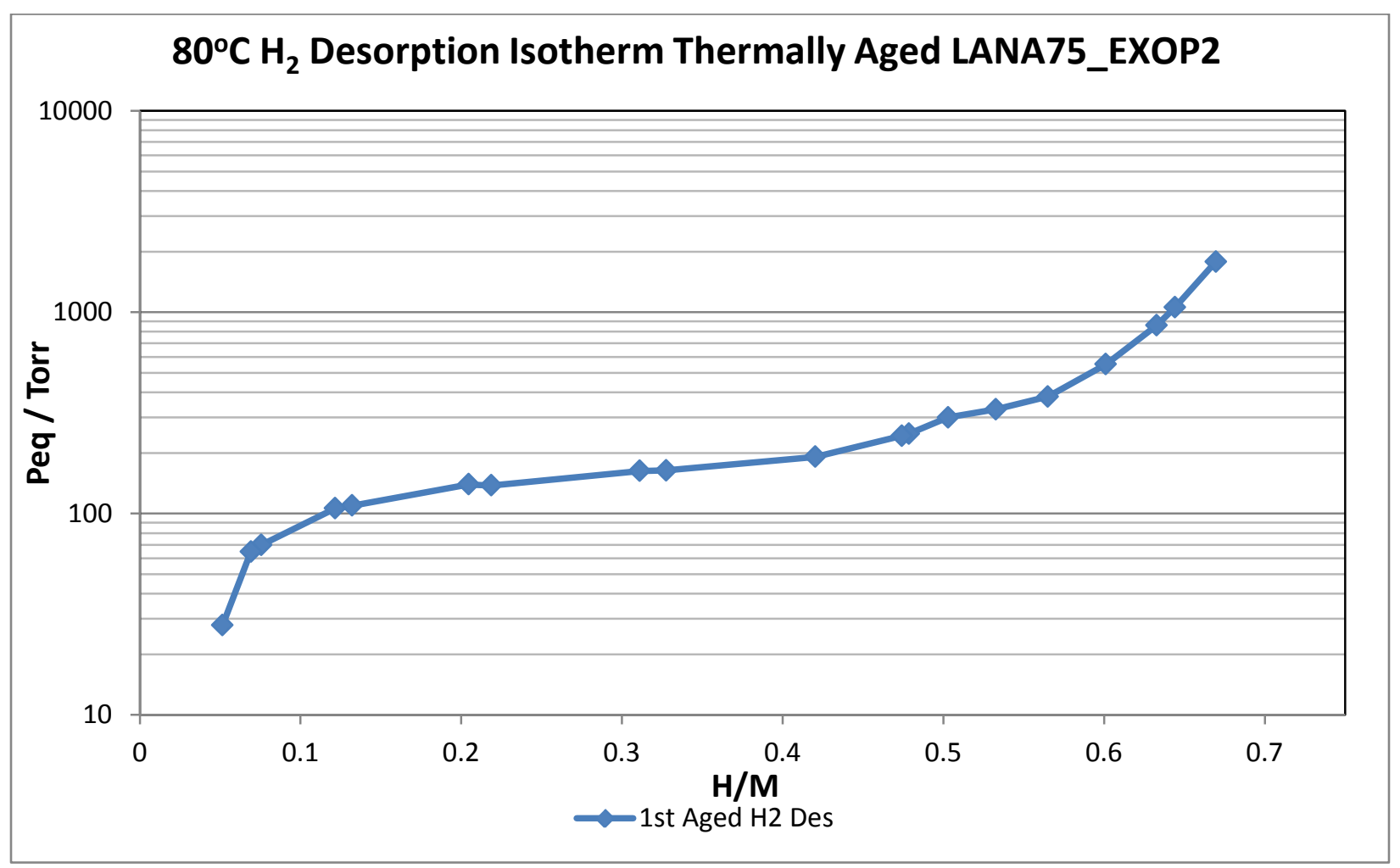


Figure 7. $80^{\circ} \mathrm{C} \mathrm{D}_{2}$ isotherms from a lot of Ergenics LANA75 (lot 1316-V-2). Virgin material results are compared to a desorption isotherm from material aged for $\sim 1$ month at $240^{\circ} \mathrm{C}$ under high hydrogen pressure. A clear plateau pressure depression is observed, and a small dual plateau is observed beginning at $\mathrm{D} / \mathrm{M} \sim 0.5$.

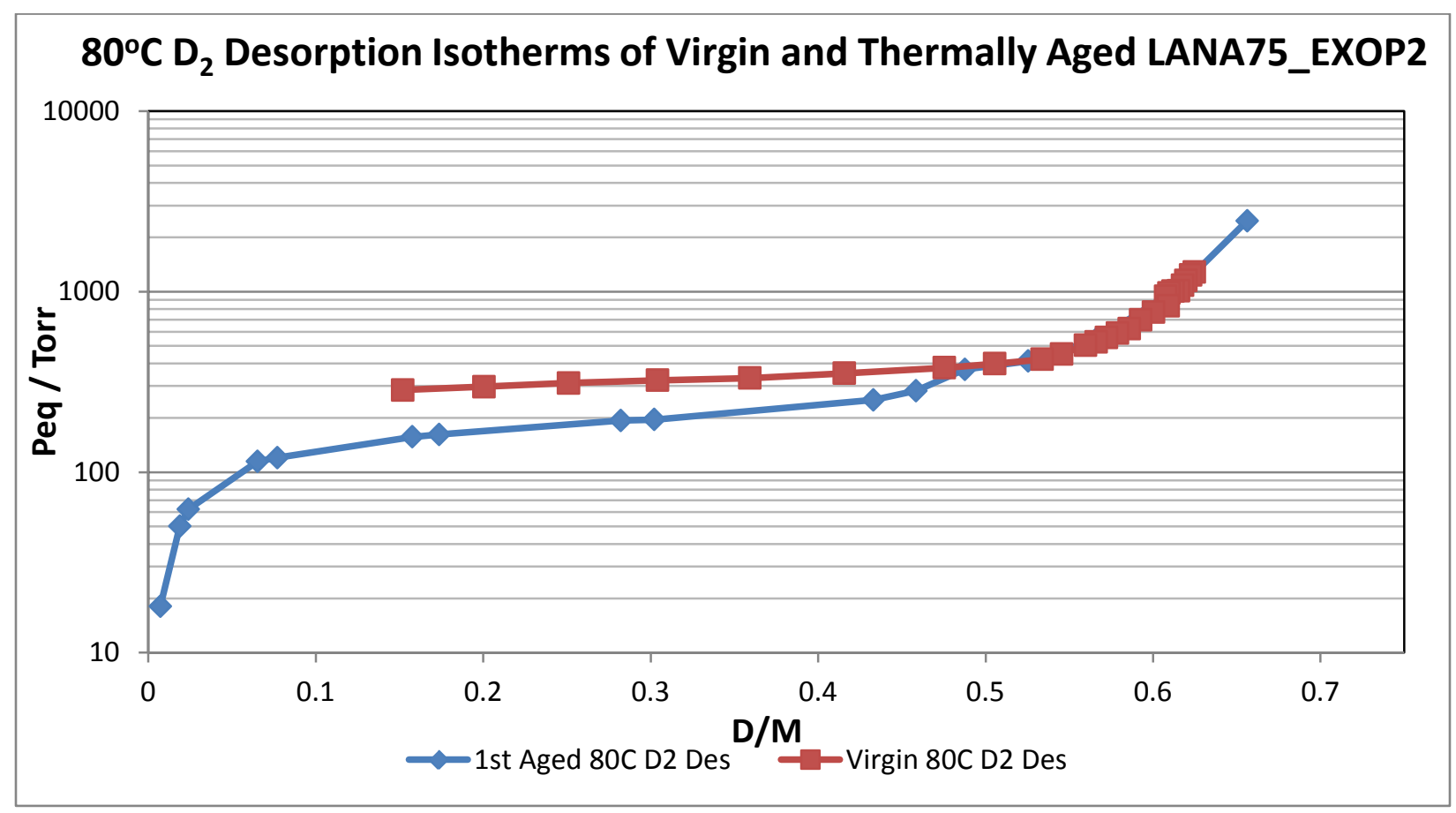


Figure 8. $80^{\circ} \mathrm{C}_{2}$ isotherms from a second lot of Ergenics LANA75 (TCON blend). Virgin material results are compared to a desorption isotherm from material aged for $\sim 1$ month at $240^{\circ} \mathrm{C}$ under high hydrogen pressure. A clear plateau pressure depression is observed and a small dual plateau is observed beginning at $\mathrm{H} / \mathrm{M} \sim 0.5$.

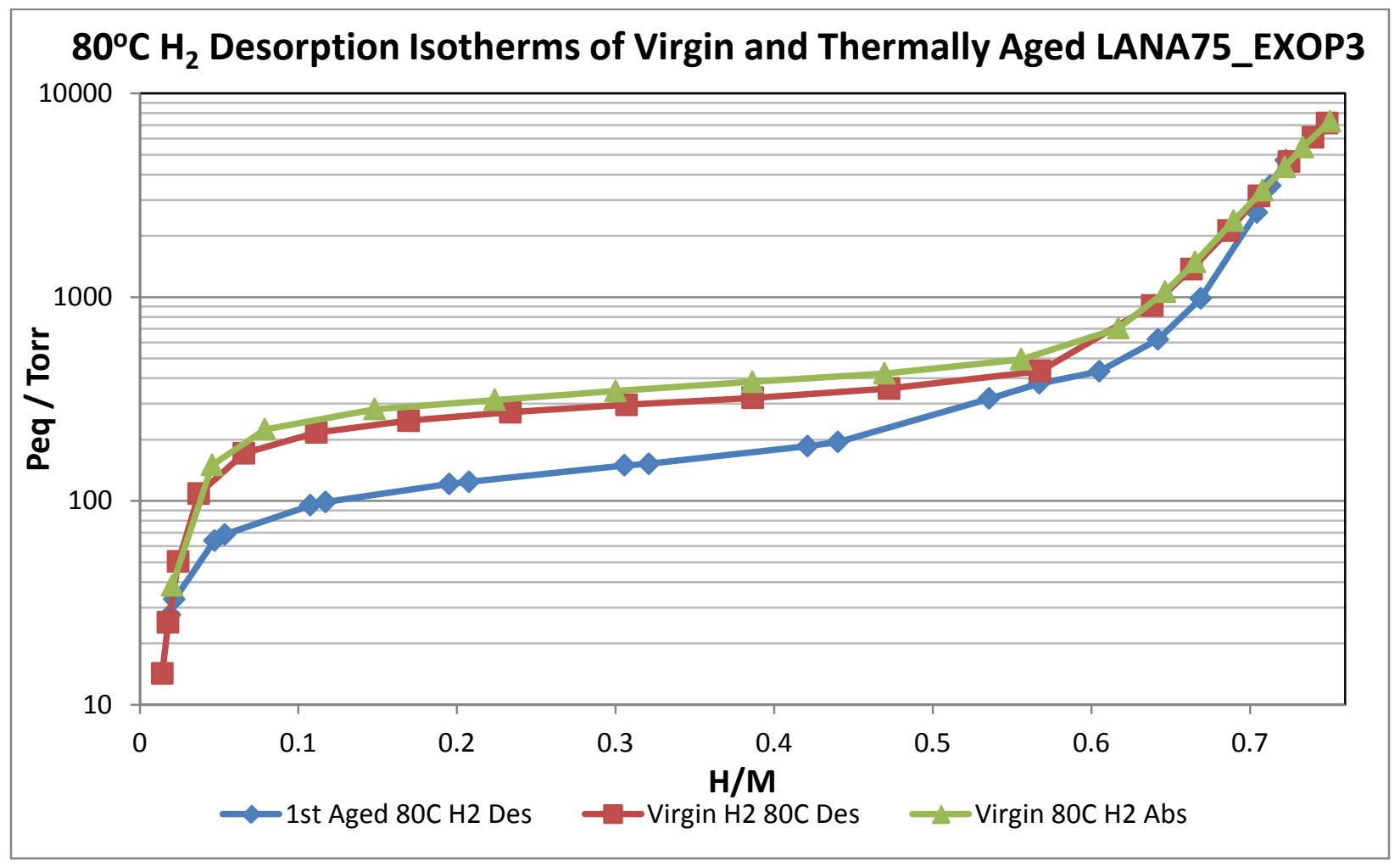


Figure 9. $80^{\circ} \mathrm{C} \mathrm{D}_{2}$ isotherms from a second lot of Ergenics LANA75 (TCON blend). Virgin material results are compared to a desorption isotherm from material aged for $\sim 1$ month at $240^{\circ} \mathrm{C}$ under high hydrogen pressure. A clear plateau pressure depression is observed and a small dual plateau is observed beginning at $\mathrm{D} / \mathrm{M} \sim 0.5$.

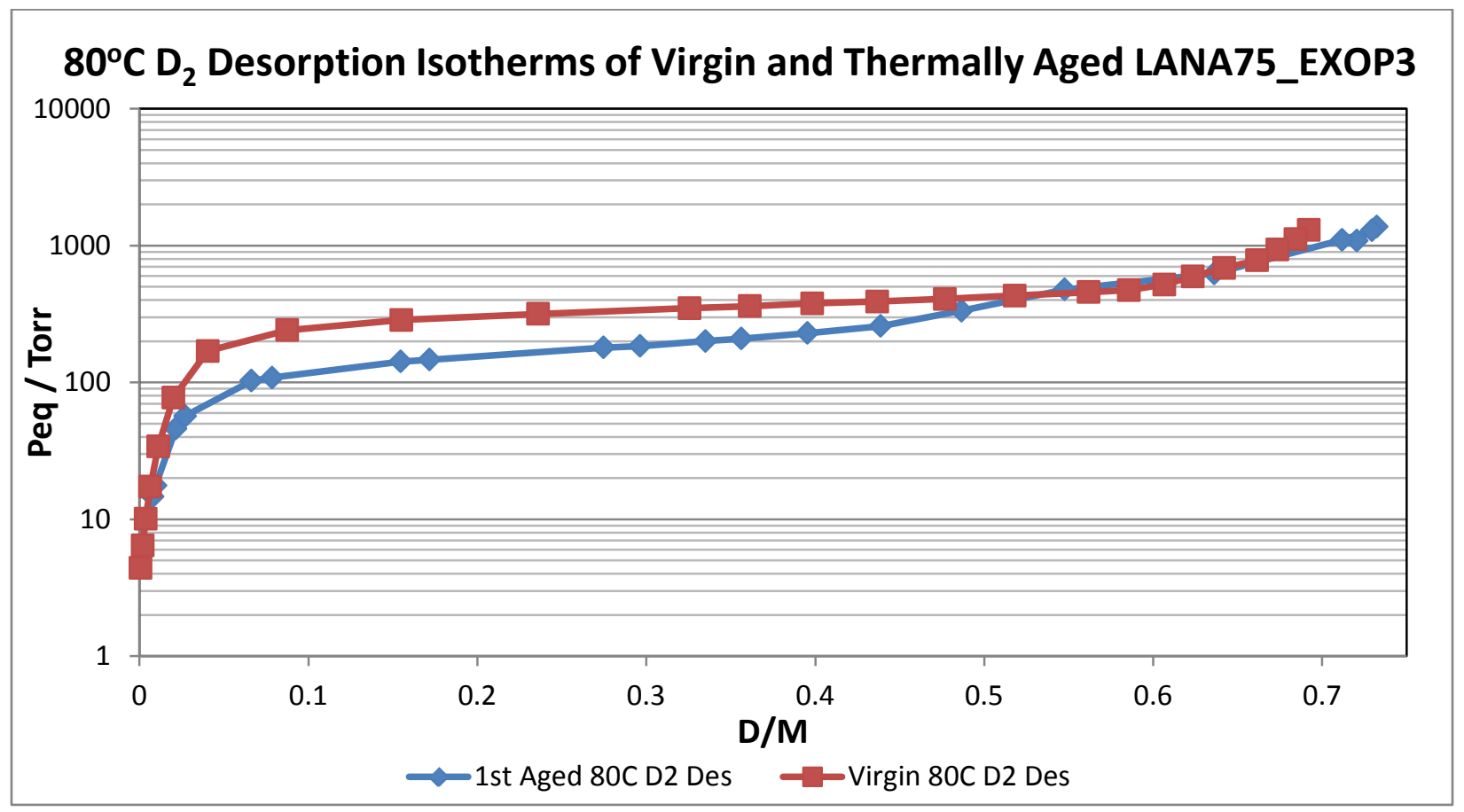


Figure 10. $80^{\circ} \mathrm{CD}_{2}$ isotherms from a lot of Ergenics LANA75 (lot 1316-V-2). Virgin material results are compared to isotherms from material aged for $\sim 1$ week at $240^{\circ} \mathrm{C}$ under high hydrogen pressure. Plateau pressure depression is just beginning and a dual plateau may be forming. Two sequential isotherm cycles were determined to asses if any changes occurred due to cycling (none noted) and to replicate the transition point between plateaus.

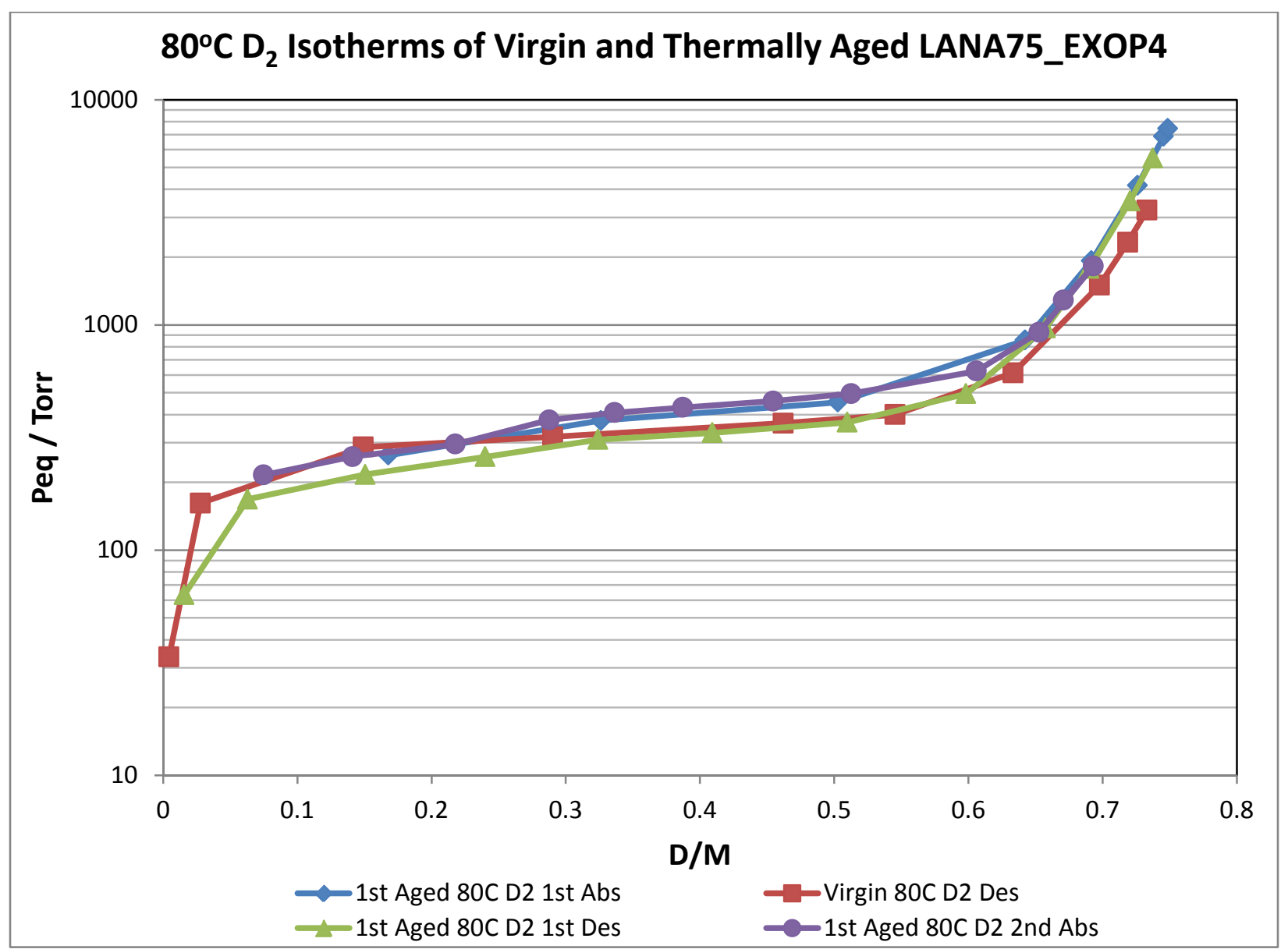


Figure 11. $80^{\circ} \mathrm{CD}_{2}$ isotherms from a lot of Ergenics LANA75 (lot 1316-V-2). Virgin material results have been removed to focus on the possible dual plateau structure from material aged for $\sim 1$ week at $240^{\circ} \mathrm{C}$ under high hydrogen pressure beginning to form in the absorption isotherm near $D / M \sim 0.25$, which is more pronounced in the absorption isotherms.

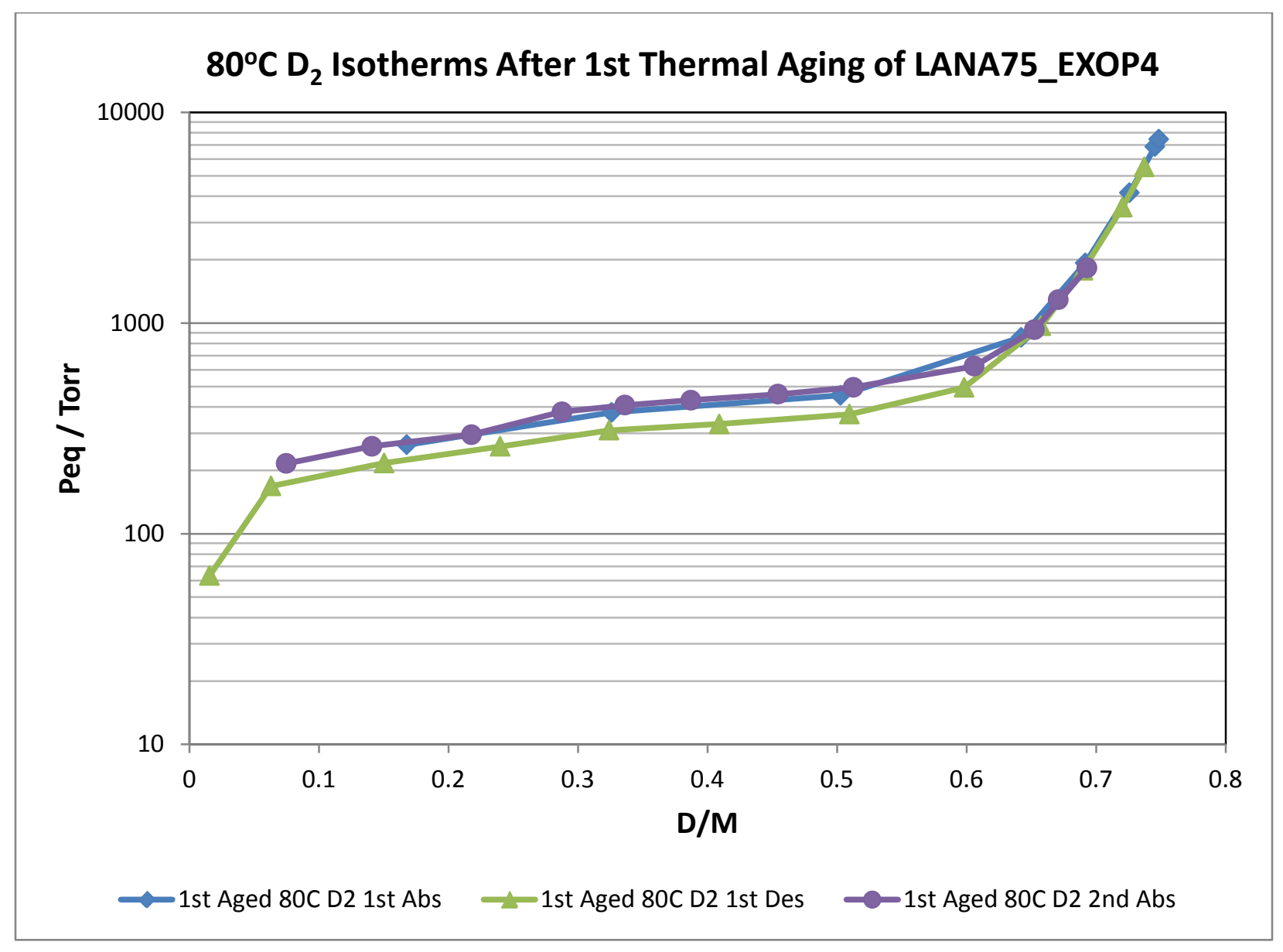


Figure 12. $80^{\circ} \mathrm{CD}_{2}$ isotherms from a second lot of Ergenics LANA75 (TCON blend). Virgin material results are compared to isotherms from material aged for $\sim 1$ week at $240^{\circ} \mathrm{C}$ under high hydrogen pressure. Plateau pressure depression is just beginning and a dual plateau may be forming.

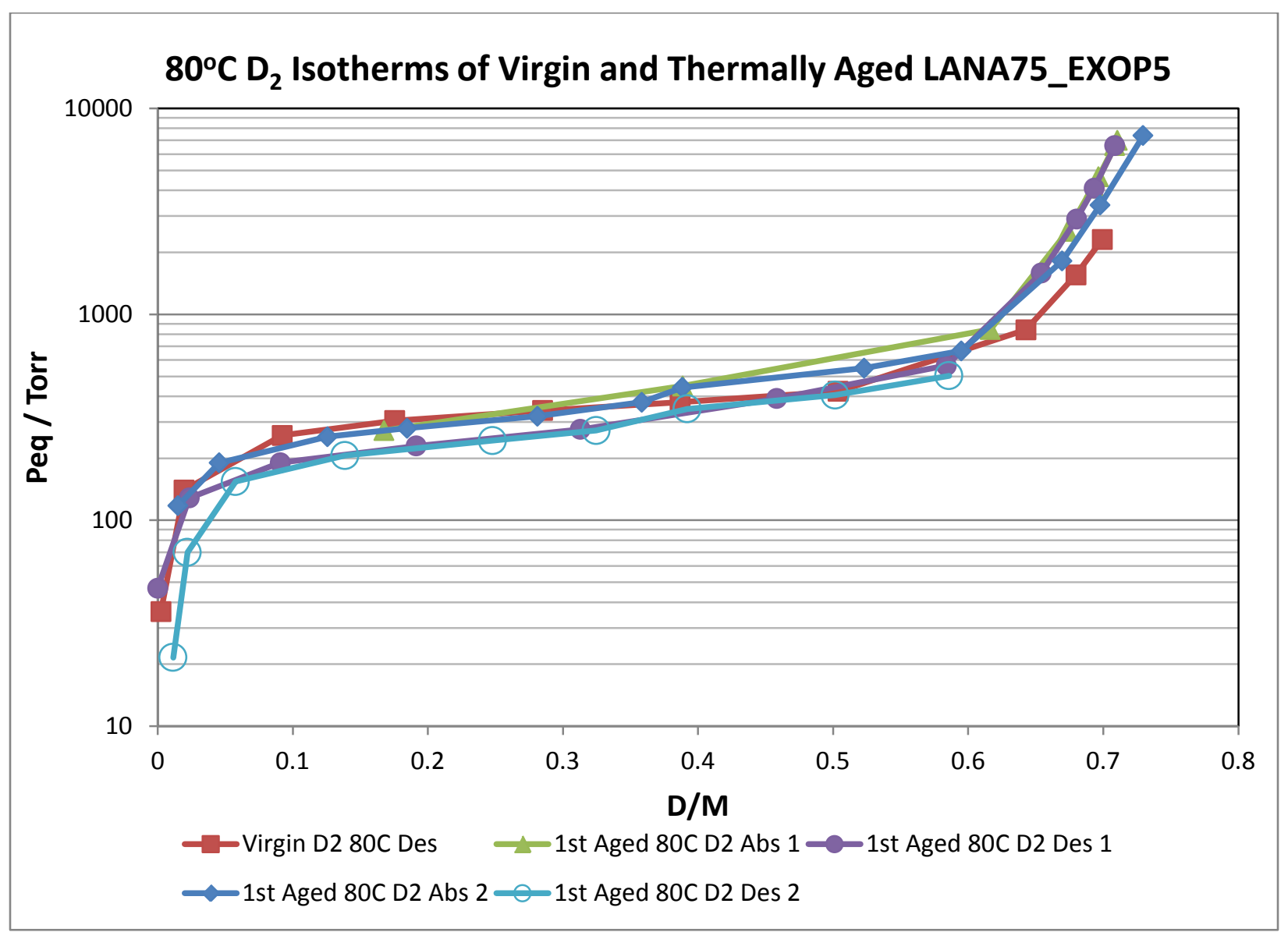


Figure 13. $80^{\circ} \mathrm{CD}_{2}$ isotherms from a second lot of Ergenics LANA75 (TCON blend). Virgin material results have been removed to more clearly show the possible dual plateau structure from material aged for $\sim 1$ week at $240^{\circ} \mathrm{C}$ under high hydrogen pressure beginning to form in the absorption isotherm near $\mathrm{D} / \mathrm{M} \sim 0.38$.

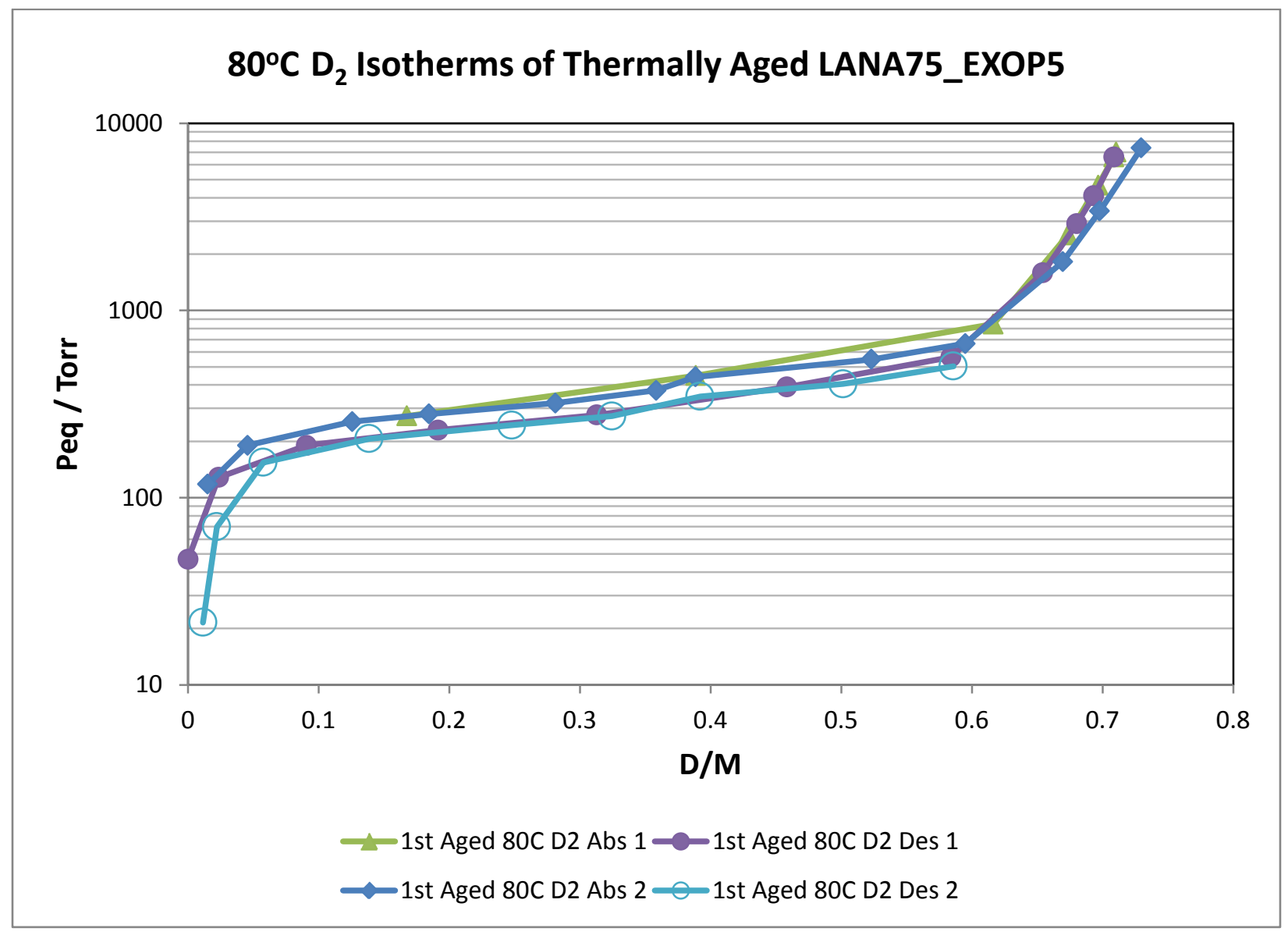


Figure 14. Merged $80^{\circ} \mathrm{C} \mathrm{D}_{2}$ isotherms from a second lot of Ergenics LANA75 (TCON blend). The data points from the separate isotherms shown in Fig. 13 have been combined into single absorption and desorption curves to more clearly show the start of the development of a dual plateau at $D / M \sim 0.4$ in the absorption isotherm. The transition in the desorption isotherm is not as clear. ('Merged' means the separate isotherm data points were combined into one set and sorted in order of increasing pressure with no averaging or smoothing. The reproducibility of isotherm points is indicated by the low $\mathrm{D} / \mathrm{M}$ region (<.05) as .02-.03 D/M units.)

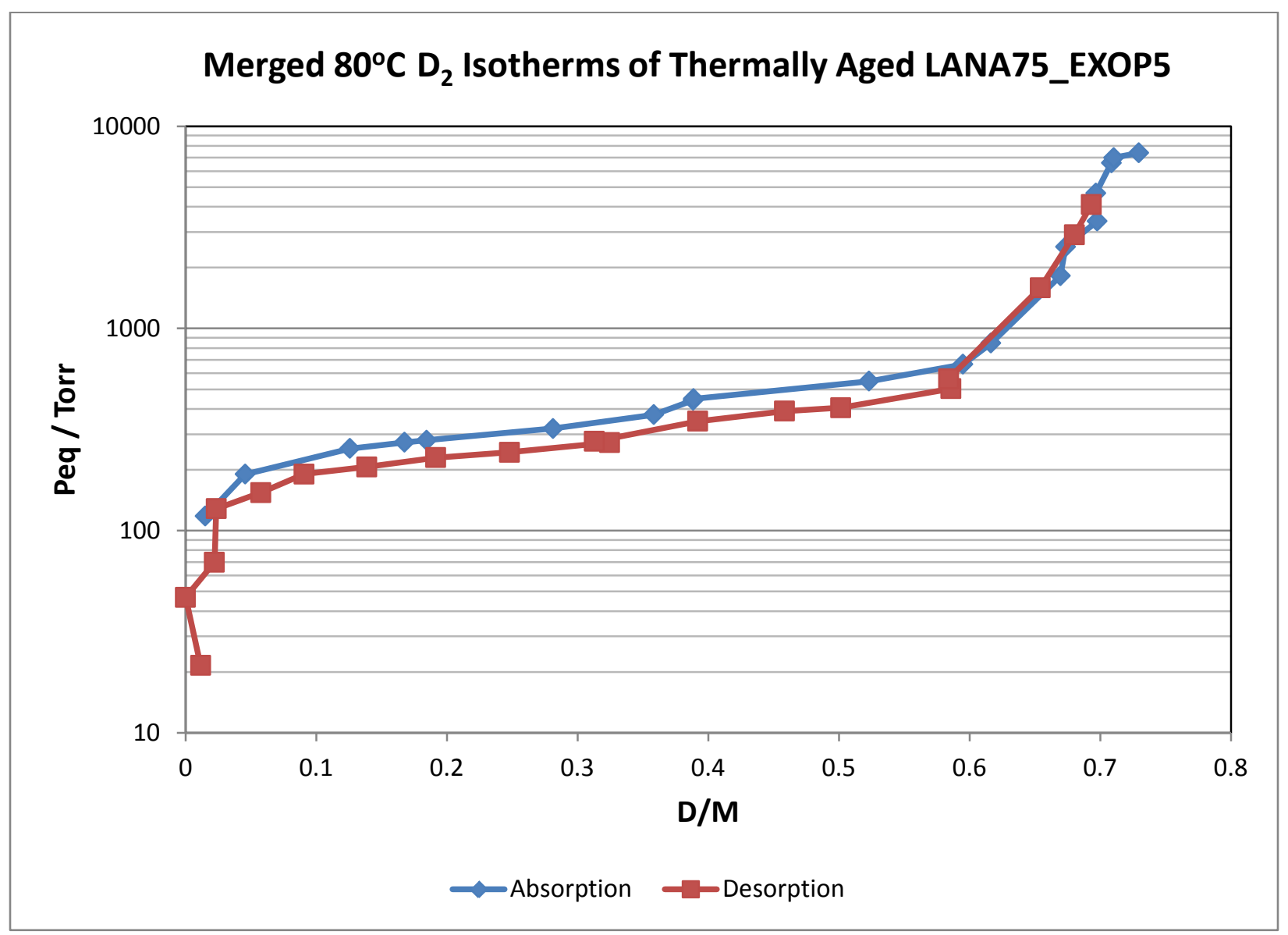


Figure 15. $150^{\circ} \mathrm{CD}_{2}$ isotherms from a second lot of Ergenics LANA75 (TCON blend). Virgin material results are compared to a partial isotherm from material aged for $\sim 1$ week at $240^{\circ} \mathrm{C}$ under high hydrogen pressure. Plateau pressure depression is noted, confirming such in LANA75 at different temperatures (prior results showed that it occurred at all temperatures for LANA85).

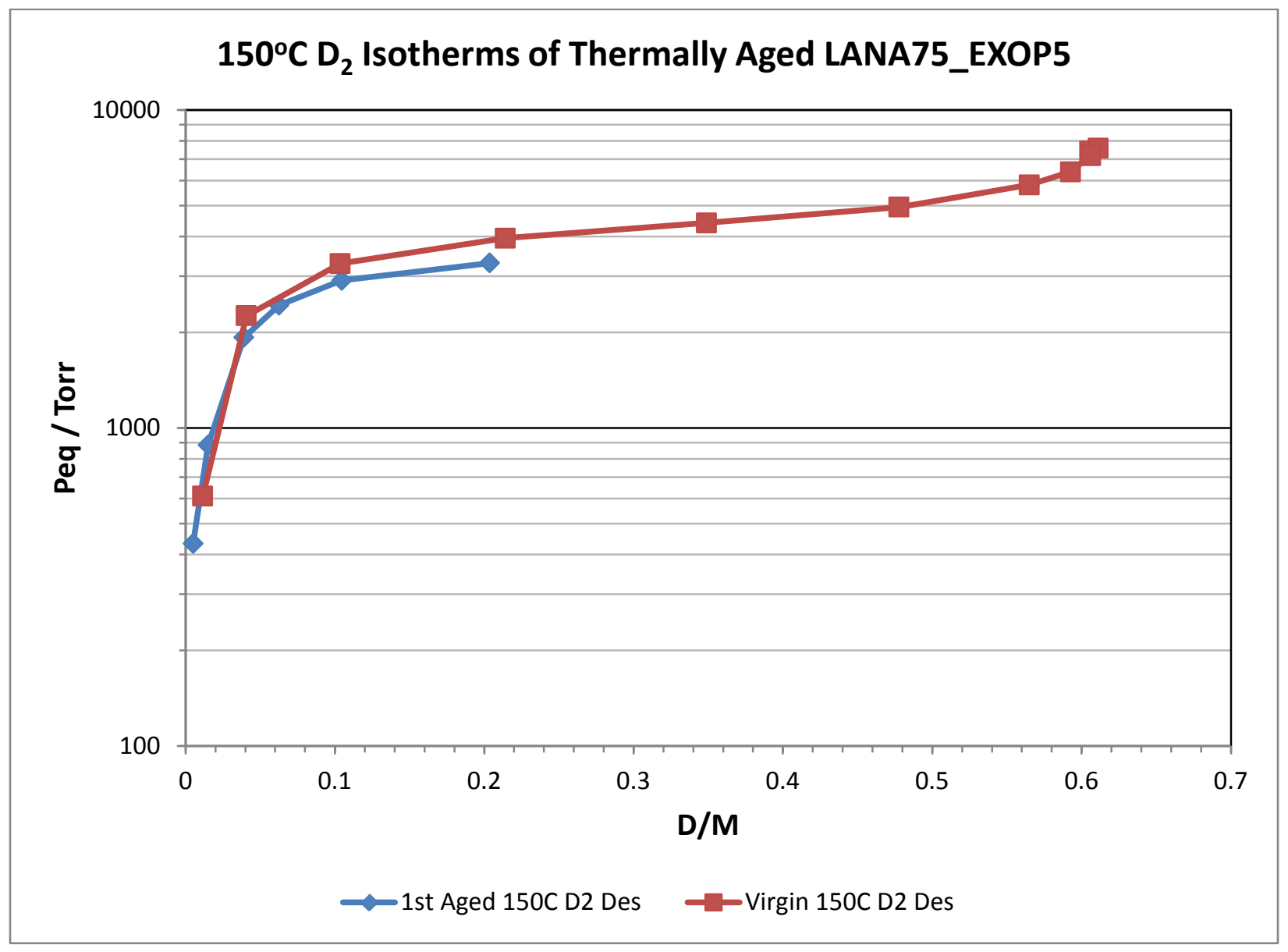


Figure 16. $\mathrm{H}_{2}$ isotherms from a LANA30 (LANA0.3) material showing dual plateau isotherms in virgin material. (Isotherms obtained from prior work.)

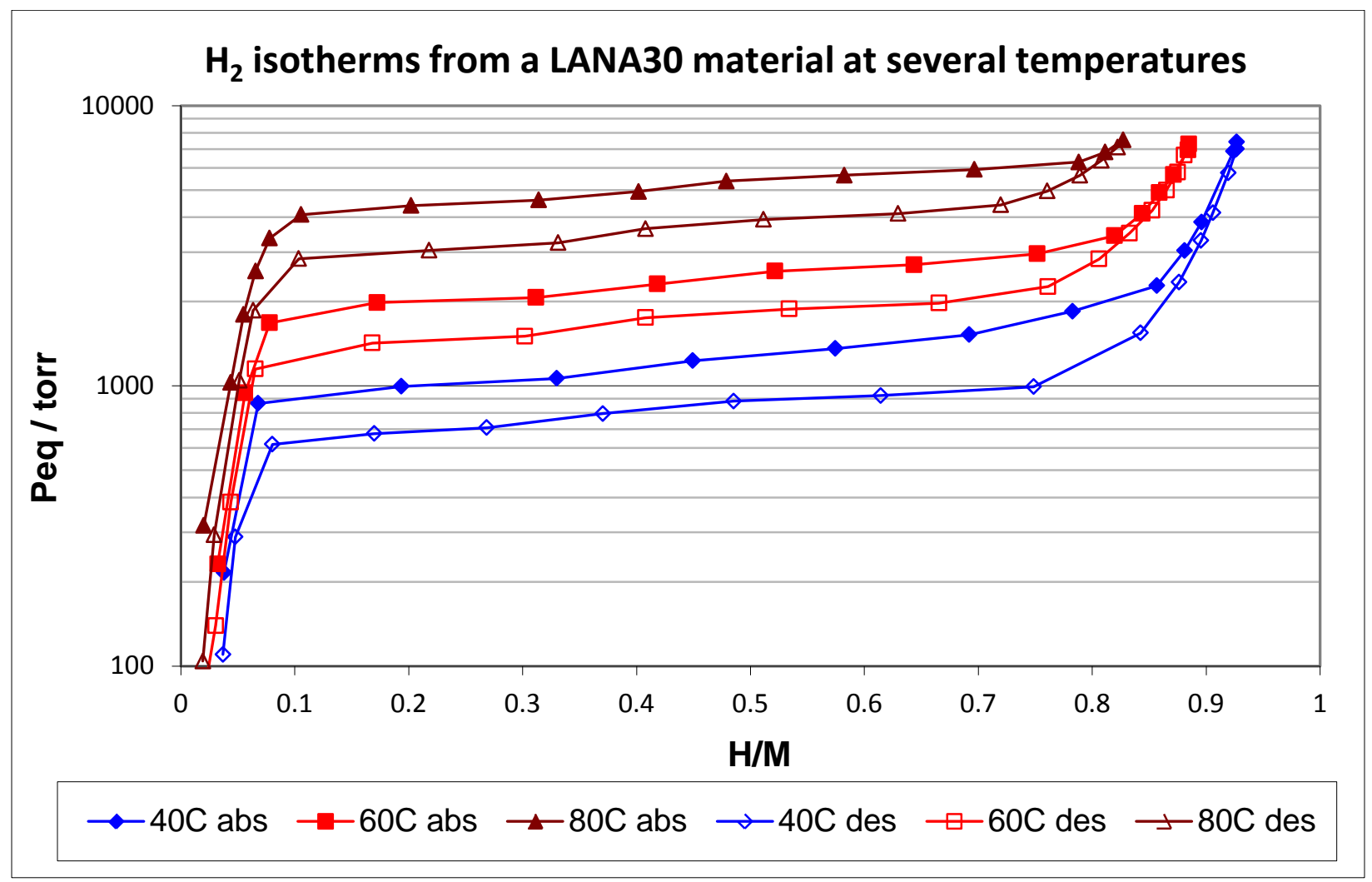

